\title{
O Lúdico e a Ludicidade nos Cadernos de Números e Operações do PNAIC ${ }^{1}$
}

\author{
Lo juguetón y la alegría em los libros de los números y Operaciones de lo \\ PNAIC
}

The playful and playfulness in books of numbers and operations on PNAIC

Karen Lapuente Souza ${ }^{2}$

Cinthia Pacífico Gonçalves ${ }^{3}$

Dra. Marta Cristina Cezar Pozzobon ${ }^{4}$

\begin{abstract}
Resumo
Neste artigo, intencionamos problematizar os discursos sobre o lúdico para ensinar Números e Operações propostos nos cadernos do Pacto Nacional pela Alfabetização na Idade Certa - PNAIC, publicados no ano de 2014. Salientamos também que as discussões empreendidas nesta produção fazem parte de um Projeto de Pesquisa proposto em rede com quatro Universidades do interior do Rio Grande do Sul. O artigo analisa os discursos sobre o lúdico e ludicidade nos cadernos de Matemática do Pacto Nacional pela Alfabetização na Idade Certa (2014). Propõe-se a responder a seguinte questão investigativa: Como os discursos sobre o lúdico e ludicidade são propostos nos cadernos de Alfabetização Matemática do PNAIC? O material analítico são os excertos dos cadernos que envolvem o eixo Números e Operações, nos cadernos 2, 3 e 4 . Nestes materiais analisamos os discursos sobre o lúdico para ensinar matemática e suas implicações no processo de ensino.
\end{abstract}

Palavras-Chave: Docência, Lúdico, Matemática, PNAIC.

\section{Resumen}

En este artículo se pretende problematizar los discursos sobre la lúdica para enseñar números y las operaciones propuestas en los cuadernos del Pacto Nacional para la Educación en la Era uno - PNAIC, publicado en el año 2014. También hacemos hincapié en que las discusiones llevadas a cabo en esta producción son parte de un proyecto de investigación red propuesta con cuatro universidades en el interior de Rio Grande do Sul. el artículo analiza el discurso sobre la diversión y el juego en los libros de Matemáticas del Pacto Nacional para la Educación en la Era Uno (2014). Se propone dar respuesta a la siguiente pregunta de investigación: ¿Cómo se propone el discurso sobre la diversión y el juego en el contrato de Alfabetización Matemáticas PNAIC? El material analítico son los extractos de los cuadernos que se usan números y eje de operaciones en el rollo 2, 3 y

\footnotetext{
${ }^{1}$ Programa Nacional pela Alfabetização na Idade Certa.

${ }^{2}$ Universidade Federal do Pampa - Unipampa: Jaguarão, Rio Grande do Sul; Brasil. klapuentesouza@ gmail.com

${ }^{3}$ Universidade Federal do Pampa - Unipampa: Jaguarão, Rio Grande do Sul; Brasil cinthiapacifico@hotmail.com
}

${ }^{4}$ Doutora em Educação; Universidade Federal do Pampa - Unipampa: Jaguarão, Rio Grande do Sul, Brasil. marta.pozzobon@hotmail.com 
4. En estos materiales se analizan los discursos sobre la lúdica para enseñar matemáticas y sus implicaciones en el proceso del enseñanza.

Palabras clave: Enseñanza, Juguetón, Matemáticas, PNAIC

\begin{abstract}
In this article we intend to problematize discourses on the playful to teach proposed Numbers and Operations in the notebooks of the National Pact for Literacy in the Age One - PNAIC, published in the year 2014. We also emphasize that the discussions undertaken in this production are part of a Research Project proposed network with four universities in the interior of Rio Grande do Sul. the article analyzes the discourse on the fun and playfulness in Mathematics books of the National Pact for Literacy in the Age One (2014). It is proposed to answer the following question investigative: How the discourse on the fun and playfulness are proposed in the contract Literacy Math PNAIC? The analytical material are the excerpts from the notebooks involving Numbers and Operations axis on the roll 2,3 and 4. In these materials we analyze the discourses on the playful to teach mathematics and its implications in the learning process. In this article we intend to problematize discourses on the playful to teach proposed Numbers and Operations in the notebooks of the National Pact for Literacy in the Age One - PNAIC, published in the year 2014. We also emphasize that the discussions undertaken in this production are part of a Research Project proposed network with four universities in the interior of Rio Grande do Sul. the article analyzes the discourse on the fun and playfulness in Mathematics books of the National Pact for Literacy in the Age One (2014). It is proposed to answer the following question investigative: How the discourse on the fun and playfulness are proposed in the contract Literacy Math PNAIC? The analytical material are the excerpts from the notebooks involving Numbers and Operations axis on the roll 2, 3 and 4. In these materials we analyze the discourses on the playful to teach mathematics and its implications in the teaching process.
\end{abstract}

Keywords: Teaching, Playfulness, Mathematics, PNAIC.

\title{
1. Introdução
}

Neste artigo, intencionamos problematizar os discursos sobre o lúdico para ensinar Números e Operações propostos nos cadernos do Pacto Nacional pela Alfabetização na Idade Certa - PNAIC, publicados no ano de 2014. Salientamos, também, que as discussões empreendidas nesta produção fazem parte de um Projeto de Pesquisa proposto em rede com quatro Universidades do interior do Rio Grande do $\mathrm{Sul}^{5}$.

Destacamos que o PNAIC é uma política de governo em que os estados e os municípios selam um acordo para assegurar que todas as crianças estejam alfabetizadas aos oito anos de idade, ao final do $3^{\circ}$ ano do Ensino Fundamental. As entidades governamentais se comprometem a alfabetizar as crianças, principalmente em língua portuguesa e em matemática, além de realizarem avaliações anuais, aplicadas pelo Instituto Nacional de Estudos e Pesquisas - INEP e apoiar os municípios nas ações do Pacto. É importante salientar que o PNAIC tem quatro eixos de atuação, que são: a formação continuada de professores alfabetizadores; os materiais didáticos e pedagógicos; as avaliações e a gestão, o controle social e a mobilização. Com isso, destacamos que para a área de educação matemática são propostos oito cadernos que abordam as seguintes temáticas: Organização do Trabalho

\footnotetext{
${ }^{5}$ Projeto de Pesquisa "A constituição da docência contemporânea para ensinar matemática nos anos iniciais do
} Ensino Fundamental”, certificado no CEP pelo nº 869824. 

e-ISSN 2016/Atual: 2525-7870 | e-ISSN 2015/2016: 2447-018X

Pedagógico; Quantificação, Registros e Agrupamentos; Construção do Sistema de Numeração Decimal; Operações na Resolução de Problemas; Geometria; Grandezas e Medidas, Educação Estatística e Saberes Matemáticos e Outros Campos do Saber. Ainda, contempla três cadernos: Educação Inclusiva; Educação Matemática do Campo e Jogos na Alfabetização Matemática. Esses cadernos são propostos como materiais para a formação continuada dos professores de anos iniciais, os quais nos interessam para a discussão que pretendemos empreender neste artigo.

Pretendemos pensar nos discursos envolvendo o lúdico, questionando essas verdades que envolvem o ensino de matemática, principalmente do bloco Números e Operações. Como diz Sartori e Duarte (2015, p. 218), as ideias que envolvem o ensinar matemática a partir de atividades lúdicas tem "ganhado cada vez mais força no discurso de Educação Matemática", e, muitas vezes, essa verdade "não é questionada, tornando-se algo naturalizado em nossas práticas".

Diante disso, pretendemos responder a seguinte questão: Como os discursos sobre o lúdico e ludicidade são propostos nos cadernos de Alfabetização Matemática do PNAIC? O material analisado faz parte dos cadernos dois, três e quatro do PNAIC, do ano de 2014, em que examinamos os excertos que tratam do lúdico para ensinar Números e Operações, considerando dois grupos de análise: "momentos, contextos e aspectos lúdicos" e "atividades e situações lúdicas".

No artigo, trazemos na próxima seção algumas discussões teóricas, depois os caminhos da pesquisa, descrevendo os materiais, na outra seção, apresentamos as análises e na última parte, tecemos algumas considerações.

\section{Algumas discussões teóricas e metodológicas}

Para começar as discussões teóricas, consideramos que conforme Huzinga (1993), a palavra lúdico se origina de ludus, que envolve os jogos infantis, a recreação, os jogos de azar, o teatro, dentre outros, envolve a ideia de jogos em geral, sendo substituído por jocus, que envolvia a ideia de "gracejar, troçar". Percebermos que o lúdico nesses casos está ligado com as brincadeiras, com os jogos e com as atividades que proporcionam divertimento, o que se aproxima da definição de lúdico proposta no dicionário, como brincadeira, jogos e divertimento (FERREIRA, 2009).

De acordo com Brougère (1998, p. 107), existe uma cultura lúdica, ou melhor, um “(...) conjunto de regras e significações próprias do jogo que o jogador adquire e domina no contexto do seu jogo". Com isso, o que torna o jogo possível é o entendimento de uma cultura 

e-ISSN 2016/Atual: 2525-7870 | e-ISSN 2015/2016: 2447-018X

lúdica, de um conjunto de referências que possibilitam "interpretar como jogo atividades que poderiam não ser vistas como tais por outras pessoas” (BROUGÈRE, 1998, p. 108). Essas ideias se aproximam dos estudos de Muniz (2010), que abordam "o jogo como possível mediador de uma cultura matemática, uma intermediação que é realizada por meio de uma estrutura lúdica concebida por um adulto".

Na perspectiva de um discurso da aprendizagem ativa, considera-se "que criança é a principal responsável de seu conhecimento" e o professor precisa mediar a ação docente a partir de experiências lúdicas (CARVALHO, 2014, p. 181). Neste sentindo, como aponta Carvalho (2014, p. 182), o professor fica responsável em observar as crianças e propor situações que satisfaçam os seus "interesses e necessidades", considerando a ludicidade como “condição indispensável para que as propostas sejam realizadas em sala de aula, pois é vista como um contraponto às práticas entendidas como escolarizadas e centradas no ensino de conteúdos".

Sartori (2015, p. 19) problematiza o enunciado que naturaliza o discurso em Educação Matemática Escolar que considera as "atividades lúdicas, como os jogos e as brincadeiras" no ensino de matemática. Discute que o lúdico faz parte de uma ideia sobre infância, em que "as concepções sobre o lúdico estão atreladas às ideias que se tem da infầncia”, considerando "o lúdico como um artefato que captura o aluno, pois possui a capacidade de prender sua atenção e motivá-lo" (SARTORI, 2015, p. 136). Diante de tais ideias, a autora mostra que:

(...) a ludicidade nas aulas de matemática contemplam uma série de atividades: brincadeiras, jogos, materiais concretos, música, videogame, entre outros. Por último, pontuei que a pedagogização do lúdico encontra potência na Educação Matemática porque tem a intencionalidade de desmistificar essa disciplina, considerada, muitas vezes, como sendo difícil, maçante e temida por muitos (SARTORI, 2015, p. 136-137).

Com isso, leva-nos a questionar as verdades sobre a importância do lúdico nas aulas de matemática, trazendo sobre os efeitos dessas práticas na constituição da infância e da subjetividade das crianças. Também, discute que a pedagogização do lúdico tem nos levado a esquecer que o seu uso tem servido além do entretenimento das crianças, mas tem produzido modos de ver e conceber as crianças, a infância, a escola.

Neste contexto, para realizarmos a pesquisa, partirmos de uma análise discursiva, na perspectiva de Michel Foucault (2007, p. 55), em que os discursos são tratados como ditos, não são tratados como signos, "mas como práticas". O discurso é entendido como um conjunto de enunciados, em que "[t]odo enunciado é portador de uma certa regularidade e não 
pode dela ser dissociado. Não se deve, portanto, opor a regularidade de um enunciado à irregularidade de outro [...], mas sim a outras regularidades que caracterizam outros enunciados" (FOUCAULT, 2007, p. 163).

Neste sentido, consideramos os cadernos 2, 3 e 4 do Pacto Nacional pela Alfabetização na Idade Certa que oferecem subsídios teóricos e práticos sobre o bloco/eixo Números e Operações. Esse eixo conta com os cadernos "Quantificação, Registros e Agrupamentos"; "Construção do Sistema de Numeração Decimal" e "Operações na Resolução de Problemas". Realizamos uma seleção das palavras "lúdico", "lúdica" e "ludicidade" nos cadernos de Números e Operações e identificamos que apareciam poucos resultados, buscamos também pelas palavras "brincadeiras" e "brincar" por estarem intimamente ligadas como conceito de lúdico.

A partir desta pesquisa selecionamos recortes/excertos, organizando-os em quadros para melhor visualização dos resultados coletados e para percebermos as recorrências em relação ao lúdico. Como ensina Fischer (2001), escrutinamos os materiais, operando de maneira intensiva sobre todo esse conjunto, questionando: "por que isso é dito aqui, deste modo, nesta situação, e não em outro tempo e lugar, de forma diferente?” (FISCHER, 2001, p. 205).

De acordo com os materiais analisados, observamos que emergiam duas categorias sobre como o lúdico e a ludicidade eram tratados: "momentos, contextos e aspectos lúdicos" e “atividades e situações lúdicas”. Os momentos e os contextos lúdicos permitem uma ressignificação das abordagens matemáticas, criam um espaço que vai além da abordagem tradicional do ensino de matemática, tornando o ambiente escolar um espaço que envolve, provoca e instiga o educando a aprender os conhecimentos matemáticos.

\section{Análise dos cadernos do PNAIC}

Os cadernos do PNAIC (2014) propõem atividades lúdicas através de jogos que proporcionem a aprendizagem de conteúdos matemáticos, através do respeito e da compreensão das regras que compõem os jogos, da resolução de situações-problemas. Com isso, espera-se que a criança aprenda mesmo sem ter consciência do processo que ocorre quando realiza esta atividade, aproximando o lúdico do ensino de matemática, na perspectiva de ensinar conceitos matemáticos. Isso pode ser evidenciado nos excertos abaixo: 

e-ISSN 2016/Atual: 2525-7870 | e-ISSN 2015/2016: 2447-018X

Antes, porém, refletiremos sobre o lúdico e os jogos dentro do contexto da sala de aula do ciclo de alfabetização, particularmente quando estamos interessados no domínio do SND pelo aluno. Neste texto, destacamos aspectos importantes da atividade lúdica associada à característica fundamental do jogo como atividade livre que permite propor, produzir e resolver situações-problema.

Fonte: Caderno 3 (BRASIL, 2014, p. 14, grifos nossos).

Assim, neste texto, vamos propor que, a partir de uma estrutura lúdica seja possível fazer emergir conceitos matemáticos. Nessa interlocução entre o lúdico e os conceitos, o aluno pode conceber a ideia da posição como elemento fundamental na representação das quantidades numéricas do Sistema de Numeração Decimal posicional.

Fonte: Caderno 3 (BRASIL, 2014, p. 28, grifos nossos).

Em situações de brincadeira, mais precisamente, em atividade com o uso de jogos, que permite a geração de uma realidade presente em outros contextos pedagógicos fora da escola, os educadores precisam compreender os sentidos da mediação pedagógica que o jogo pode trazer entre as questões epistemológicas e da ludicidade.

Fonte: Caderno 3 (BRASIL, 2014, p. 38, grifos nossos).

Ao elaborar um jogo com atividade matemática, o professor deve manter em vista a ludicidade que atrairá o interesse da criança. Há jogos que são enfadonhos e desinteressantes. A criança perde logo o interesse por eles.

Fonte: Caderno 3 (BRASIL, 2014, p. 39, grifos nossos).

Com isso, destaca-se que o ensino da matemática, no eixo Números e Operações, vai muito além de cálculos, de problemas e de fórmulas, mas pode proporcionar aos alunos que desenvolvam habilidades que facilitem a solução de problemas do seu cotidiano que se apresentam das mais variadas formas. Desse modo, o ensino de matemática a partir de uma perspectiva lúdica, considera a proposição de desafios e não apenas a repetição de uma técnica ensinada anteriormente. Isso, conforme os cadernos do PNAIC (2014), pode colaborar com a aprendizagem das habilidades matemáticas pelos alunos, pois essas situações podem facilitar a compreensão dos conteúdos e conceitos matemáticos. Considera-se, que:

Ao chegar à escola muitos são os conhecimentos trazidos pelas crianças. Movidas pela curiosidade investigativa, em situações envolvendo as brincadeiras comuns ao 
RELACult - Revista Latino-Americana de Estudos em Cultura e Sociedade

Revista Latinoamericana de Estudios en Cultura y Sociedad | Latin American Journal of Studies in Culture and Society V. 02, Ed. Especial, dezembro, 2016, p. 125-133 | periodicos.claec.org e-ISSN 2016/Atual: 2525-7870 | e-ISSN 2015/2016: 2447-018X

cotidiano infantil, constroem hipóteses próprias sobre quantidade, espaço, tempo, escritas numéricas, bem como se envolvem, ao explorar objetos, em ações que requerem quantificar, comparar, contar, juntar, tirar, repartir, entre outras, na resolução de pequenos problemas de modo prático e também simbólico (BRASIL, 2014, p. 6).

Isso deveria ser aproveitado pelo professor ao ensinar Números e Operações, considerando que os aspectos lúdicos tornam-se um importante instrumento na mediação dos processos de ensino e de aprendizagem, além de contribuir para o desenvolvimento social, intelectual e emocional das crianças. Nesta perspectiva, por fazer parte da formação cultural e social da criança desde seu nascimento, o lúdico poderá trazer novas possibilidades de assimilação e entendimento das noções matemáticas, sejam elas escolares ou não, pois ao brincar a criança está se desenvolvendo e produzindo novos significados para suas aprendizagens, não de maneira mecânica, mas de forma natural, autônoma para a sistematização do conhecimento. Essas ideias se aproximam do outro grupo de análise, que destacamos nos excertos abaixo.

Pode-se dizer que, mesmo antes de entrar no ensino fundamental, toda criança já vivenciou situações que podemos denominar de pré-numéricas, identificando pequenas quantidades fazendo uso do seu senso numérico. O contato com os nomes dos números em momentos lúdicos e sociais também acontece de forma variada.

Fonte: Caderno 2 (BRASIL, 2014, p. 62, grifos nossos).

Dentro de um contexto lúdico, atividades matemáticas com diferentes níveis de complexidade desafiam o raciocínio e estimulam a curiosidade de estudantes do segundo ciclo do Ensino Fundamental.

Fonte: Caderno 2 (BRASIL, 2014, p. 82, grifos nossos).

A experiência destaca a importância dos aspectos lúdicos, presentes na história contada, bem como a importância do compartilhamento de ações na sala de aula que permitem a interação dos alunos com a atividade, com o professor e entre eles.

Fonte: Caderno 2 (BRASIL, 2014, p.83, grifos nossos).

Esses excertos nos levam a suspeitar que os momentos, as situações e os aspectos lúdicos são orientações aos professores, para que estejam mediando o trabalho pedagógico, considerando os interesses das crianças e servindo para que aprendem mais e melhor a 
matemática escolar. Com isso, acaba-se sugerindo o uso de histórias, das vivências anteriores das crianças e da graduação das atividades propostas, a fim de desenvolver o raciocínio e estimular a curiosidade. Notamos que a ludicidade é entendida como uma forma de oportunizar as crianças experiências de contato com os mais variados conhecimentos de forma acessível e compreensível. Assim, a escola pode ser sim um espaço de brincadeira, de descontração e de divertimento em que o processo de aprendizagem aliado a atividades lúdicas de dá de forma produtiva, útil e significativa.

\section{Algumas considerações}

A partir do que pretendíamos problematizar sobre como são propostos os discursos sobre o lúdico e ludicidade nos cadernos do PNAIC que tratam de Números e Operações, analisando os excertos, pode-se perceber que as atividades e situações lúdicas são instrumentos em potencial no ensino de conceitos e de concepções matemáticas, pois permitem que aspectos mais específicos dessa área do conhecimento, que geralmente são ensinadas e aprendidas de forma complexa, passem a ser abordadas, dentro de uma perspectiva que leva em consideração uma democratização dos conhecimentos matemáticos, ou seja, respeita e valoriza os conhecimentos aprendidos em outros contextos, em contextos não escolares. Assim, estes cadernos disponíveis aos professores dos anos inicias proporcionam ao educador algumas formas de inserção do lúdico na sala de aula, proporcionando aos educandos que aprendam matemática de forma prazerosa e com motivação.

Isso nos leva a pensar que, além de trazer sobre os modos de ensinar e de aprender, o lúdico e a ludicidade produzem modos de conceber a docência para ensinar matemática, modos de se produzir os alunos dos anos inicias e modos de se dizer como se ensina e se aprende Números e Operações. Existiriam outros modos de ensinar Números e Operações, além do lúdico?

\section{Referências}

BRASIL, Secretaria de Educação Básica. Diretoria de Apoio à Gestão Educacional. Pacto Nacional pela Alfabetização na Idade Certa: Quantificação, registros e agrupamentos. Brasília: MEC, SEB, 2014a.

BRASIL, Secretaria de Educação Básica. Diretoria de Apoio à Gestão Educacional. Pacto Nacional pela Alfabetização na Idade Certa: Construção do sistema de numeração Decimal. Brasília: MEC, SEB, 2014b. 

e-ISSN 2016/Atual: 2525-7870 | e-ISSN 2015/2016: 2447-018X

BRASIL, Secretaria de Educação Básica. Diretoria de Apoio à Gestão Educacional. Pacto Nacional pela Alfabetização na Idade Certa: Operações na resolução de problemas. Brasília: MEC, SEB, 2014c.

BROUGÉRE, Gilles. A criança e a cultura lúdica. Revista Faculdade de Educação, São Paulo, v. 24, n. 2, p. 103-116, jul./dez., 1998.

CARVALHO, Rodrigo Saballa de. Aprendizagem e formação docente: uma analítica da ordem do discurso do ProInfantil. Revista Linhas Críticas, Brasília, v. 20, n. 41, p. 167-187, 2014.

FERREIRA, Aurélio Buarque de Holanda. Novo dicionário da Língua Portuguesa. Curitiba: Editora Positivo, 2009.

FISCHER, Rosa Maria Bueno. Foucault e a análise do discurso em educação. Cadernos de Pesquisa. n. 114, p. 197-223, nov., 2001.

FOUCAULT, Michel. Arqueologia do saber. Rio de Janeiro: Forense Universitária, 2007.

HUZINGA, Johan. Homo ludens: o jogo como elemento da cultura. São Paulo: Perspectiva, 1993.

MUNIZ, Cristiano Alberto. Brincar e jogar: Enlaces teóricos e metodológicos no campo da educação matemática. Belo Horizonte: Autêntica, 2010.

SARTORI, Alice Sthefanie Tapi. O lúdico na Educação Matemática Escolar: Efeitos na constituição do sujeito infantil contemporâneo. 2015. 197 f. Dissertação (Mestrado em Educação Científica e Tecnológica) - Pós-Graduação em Educação Científica e Tecnológica, Universidade Federal de Santa Catarina (UFSC), 2015.

SARTORI, Alice Sthefanie Tapi; DUARTE, Cláudia Glavam. Práticas matemáticas na Educação Matemática Escolar: a escola nos fluídos da Modernidade líquida. Revista Educação Matemática Pesquisa, São Paulo, v. 17, n. 2, p. 216-231, 2015. 